\title{
An Evaluation of MM Anupol Poultry Farm through SWOT Analysis: An IFE and EFE Matrix Approach
}

\author{
Noemi C. Vega ${ }^{1}$ and Felipe E. Balaria ${ }^{2}$, Ph.D.
}

${ }^{1}$ Faculty, Nueva Ecija University of Science and Technology, San Isidro Campus

${ }^{2}$ Faculty, Graduate School, Nueva Ecija University of Science and Technology

\begin{abstract}
The study aimed to evaluate the existing business of MM Anupol Poultry Farm through itsInternal Strengths and Weaknesses and External Opportunities and Threats using the Internal Factor Evaluation (IFE) and External Factor Evaluation (EFE) Matrices. This study utilized descriptive research design and found out that: the poultry farm is a stable business which already exists for 58 years and under the closed corporation form of business; for the IFE Matrix, the poultry is considered a strong in their industry position which means that its internal position is good;for the EFE Matrix, the poultry is responding in an excellent manner to existing opportunities and threats of the industry; and the firm's strategies is capitalizing on its opportunities effectively and minimizing the effects of potential threats efficiently.
\end{abstract}

Keywords-External Factor Evaluation, Internal Factor Evaluation, Poultry Farm, SWOT Analysis.

\section{INTRODUCTION}

Layer farming is a profitable business venture with growing demand for egg. It provides venturing farms with income and employment opportunities of secure, return and profit over investment[1]. Running a chicken farm requires more than just an agricultural know-how, if one is interested to be a chicken farmer, he must also think like a business person while growing their brand. Choosing a focus, establishing a brand, raising their chickens, improving the quality of produced eggs, proper record keeping and building their business are all part of chicken farming. Then, as the farm business grows, the owner or the manager must be knowledgeable enough on the different functional areas of business like management, finance, marketing, technical and network to grow the business.

San Isidro, which is a 2nd class municipality in the province of Nueva Ecija, Philippines, has a population of 54,023 people according to the 2017 census. The community in the said municipality primarily depends on rice and vegetable farming, poultry and piggery. If one passes by in the town, a number of vendors selling day olds and culled chickens in the street would be noticed, which is considered as one of the sources of income of the people in the municipality. One of most popular egg layer farm businesses in the place is the MM Anupol Poultry which is a Closed Corporation owned by the Anupol family. The business has been inherited by the family from their late father Manuel Anupol who started the business while he was raising his kids and was able to manage and to sustain the business and has now become his inheritance to his children to secure them financially.

This study was conducted to evaluate the MM Anupol Poultry Farm which is a business operating as the biggest egg layer farm in the municipality of San Isidro using the SWOT Analysis specifically the Internal Factor Evaluation (IFE) and External Factor Evaluation (EFE) Matrix of Fred David (2011). Furthermore, the purpose of using SWOT Analysis is for the business owners to identify their strengths that provide an exploration of the firm's leads over its adversaries. "Weaknesses consider areas in which the companies are at a competitive disadvantage and must be overcome before it turned out the business success into failure. Opportunities are a list of untapped markets or business developments. Threats explore the external environment that could affect the company, including technological, environmental and regulatory factors [2].”

\section{Objectives of the Study}

The study aimed to evaluate the existing business of Anupol family which is the MM Anupol Poultry Farm through the use of its Internal Strengths and Weaknesses and External Opportunities and Threats using the IFE and EFE Matrix. Moreover, it is intended to propose a strategic solution to these weaknesses found by the business owners to sustain the profitability and good financial condition of the corporation. Also, the study aimed to come up with the 
game plan to withstand the threats along their way especially the epidemic of bird flu which had been an issue in the industry.

\section{RESEARCH METHODOLOGY}

This study utilized descriptive research design. According to authors in [3] as cited by[4], "descriptive research describes what is. It involves the description, recording, analysis and interpretation of the present nature, composition or processes of phenomena".

The gathering of data was conducted during August of 2018at MM Anupol Poultry through their managing owner in the person of Amelito Baylon Anupol and his employees at San Roque, San Isidro, Nueva Ecija, Philippines using questionnaire and unstructured interview. The study used the Internal Factor Evaluation (IFE) and
External Factor Evaluation (EFE) Matrix as tools to evaluate the business of MM Anupol Poultry Farm. "The internal and external factor evaluation matrices have been introduced by Fred R. David (2011) in his book Strategic Management". "According to him, both tools are used to summarize the information gained from company's external and internal environment analysis. The summarized information is evaluated and used for further purposes, such as, to build SWOT analysis [5]."The tools are nearly identical so it can help in enhancing the company especially in overcoming its weaknesses, taking advantage of its opportunities and decreasing threats.

Scoring: Each response to every item was evaluated based on the following scale and verbal interpretations:

\section{Responses}

\begin{tabular}{|c|c|c|c|}
\hline \multicolumn{2}{|c|}{ Internal Strengths and Weaknesses } & \multicolumn{2}{c|}{ External Opportunities and Threats } \\
\hline 1 & Major Weakness & 1 & Poor \\
\hline 2 & Minor Weakness & 2 & Average \\
\hline 3 & Minor Strength & 3 & Above average \\
\hline 4 & Major Strength & 4 & Superior \\
\hline
\end{tabular}

Statistical tools utilized in this study were weight, rating and weighted score.

\section{RESULTS AND DISCUSSIONS}

Table.1: Internal Factor Evaluation Matrix for MM Anupol Poultry Farm

\begin{tabular}{|c|c|c|c|}
\hline Internal Strengths & Weight & Rating & Weighted Score \\
\hline $95 \%$ of the 50,000 chickens are producing quality eggs & 0.10 & 4 & 0.40 \\
\hline 70 to 80 weeks of productive laying phase of chickens & 0.15 & 4 & 0.60 \\
\hline Low disease incidence encountered & 0.05 & 3 & 0.15 \\
\hline Well supplemented vaccines and medicines & 0.05 & 4 & 0.20 \\
\hline Proper litter management & 0.05 & 3 & 0.15 \\
\hline Little noise in the location of the farm & 0.05 & 3 & 0.15 \\
\hline High degree of specialization in farm management & 0.10 & 3 & 0.30 \\
\hline Rural labor force in the site & 0.05 & 3 & 0.15 \\
\hline Low environmental pollution & 0.05 & 3 & 0.15 \\
\hline Huge number of distributors in the town & 0.05 & 3 & 0.15 \\
\hline \multicolumn{4}{|l|}{ Internal Weaknesses } \\
\hline Minimal control of biosecurity system & 0.10 & 1 & 0.10 \\
\hline Break-even profit during the summer season & 0.05 & 2 & 0.10 \\
\hline Lack of high-technology poultry system & 0.05 & 2 & 0.10 \\
\hline Low level of egg shelf life & 0.05 & 2 & 0.10 \\
\hline Location site near residential area & 0.05 & 2 & 0.10 \\
\hline Total & 1.00 & & 2.90 \\
\hline
\end{tabular}

The company having a total weighted score of 2.90 which is higher than 2.50 is consider as strong in their industry position. It means that the company's internal position is good. 


\section{Internal Strengths}

Factors like 70-80 weeks of productive laying phase is considered as a major strength since by normal range it is only up to 60 weeks which shows that they exceeded the life span for the chickens to lay eggs before culling procedure and they are 20 weeks over than the normal range. According to [6], "chickens start laying eggs commercially from 18-19 weeks of age and they remain laying eggs continuously until their 72-78 weeks of age." This means that the business owners have already determined the method of prolonging the life span of chickens to produce more eggs, thus, providing them optimum returns to their investments in vitamins, medicines and feeds or in their inputs.

Having a huge number of chickens laying eggs is considered by the owners as one of their major strengths since more chickens being housed in the cage means more eggs that can be produced. Notwithstanding the fact that $95 \%$ of the 50,000 chickens are producing quality eggs everyday which denotes that about 47,500 eggs are being harvested everyday giving the business a huge income.

Based on the interview conducted by the researchers, it has been disclosed that having a good management system is very significant in running a business like poultry farm since one has to use common business sense when running and operating a farm business. He added that the first step is to determine the market and see if the existing business has enough space and facility to supply the needs in the market. Having a formal education as he added is also essential as to proper management of the labor force, technical know-how in operating the farm, knowledge on proper bookkeeping and accounting and even the customer relations management and dealing with different stakeholders. The high degree of specialization in the egg production is seen as strength because it provides opportunities to perform better due to more knowledge of a specific part of the production chain and due to costs being divided over larger units [7].

With their goal of maximizing the lifespan of their chickens laying eggs, the owner has revealed that well supplemented vaccines and medicines is the key. The vaccination programme is designed by a poultry specialist and must be stringently followed until the hens reach culling age. This is also the reason of having low disease encountered by them.

As to the poultry's hygiene to avoid complaints from the people living near the area, the business has proper litter management that prevents the spread of maggots and flies. Besides, they also keep chicken manures and sell these as fertilizers for plantation and field crops which served as their additional income. As can be noted, the environmental impact of manure proper disposal can contribute considerably to the environmental impact of egg production [8].

Additionally, little noise in the poultry is maintained since chickens are stressed with noise and love music a lot.

Subsequently, the farm has 10 layer houses and they can maximize a ratio $1: 5,000$ chickens. This means that the business generates jobs and gives an opportunity to many jobless in the community including out of school youths and unemployed people in the area.

To minimize environmental pollution, the business has complied with the standards or requirements of Department of Environment and Natural Resources (DENR) to mention some of these are their compliance to continuous supply of adequate power, potable water and good access road; the place is not near the bodies of water and wetlands that are frequented by migratory fowl and it is not prone to flooding [9].

Another good aboutthe business is, there are huge numbers of distributors present since marketing chicken eggs in the Philippines is not difficult. Eggs don't go bad so soon and there is a massive demand for chicken eggs in the Philippines [10].

\section{Internal Weaknesses}

On the other hand, the respondents have also divulged some of the weaknesses of the business. One of the major weaknesses they have considered is the minimal control of biosecurity system. Biosecurity is the protection of animals from any type of infectious agent-viral, bacterial, fungal or parasitic. It is done by not permitting other animals from entering the poultry farm to bring disease and for the animal not brought to disease [11]. The manager also added that controlling people coming in and out of the poultryis another problem. That is why they cannot avoidtransmission of diseases to chickens since people can also spread diseases as they move from one facility to another [12].

Another weakness mentioned by the respondentsis that egg layer farm business has its lean season.Especially during summer break, on the months of March to May. During these months, since students are on vacation, egg consumption decreases thus, their income is onlyin the break-even point. Also, low shelf life of eggs is another weakness of the business. The U.S. Department of Health \& Human Services, 2018, mentioned that eggs can only last until two weeks and if refrigerated it lasts 3 to 5 weeks. 
Additionally, due to the fact that MM Anupol Poultry Farm is still using the conventional type of housing and the traditional feeding and watering system, it has been considered to have lack of high-technology poultry system. Knowledge on how to manage a business integrating technology is very necessary nowadays because it is a contributor for the business to become sustainable in the long range perspective.

The location site is also a weakness since it is near the residential areas.Due to several reasons, the manager haven't complied with the requirement of at least 1 kilometer away from their neighbors.

Table.2: External Factor Evaluation Matrix for MM Anupol Poultry Farm

\begin{tabular}{|l|c|c|c|}
\hline \multicolumn{1}{|c|}{ External Opportunities } & Weight & Rating & Weighted Score \\
\hline Increasing consumer demand and consciousness & 0.20 & 4 & 0.80 \\
\hline $\begin{array}{l}\text { Creating strong functional relations between the owner and the } \\
\text { stakeholders }\end{array}$ & 0.05 & 2 & 0.10 \\
\hline Availability of good quality raw materials & 0.10 & 3 & 0.30 \\
\hline Availability of high technology farm facilities & 0.15 & 3 & 0.45 \\
\hline Operating in a duopoly market structure & 0.05 & 2 & 0.10 \\
\hline \multicolumn{1}{|c|}{ External Threats } & & & \\
\hline Not favorable temperature & 0.05 & 2 & 0.10 \\
\hline Potential entry of new competitors & 0.05 & 1 & 0.05 \\
\hline High cost of inputs (raw materials and medicines) & 0.15 & 4 & 0.60 \\
\hline Disease outbreak & 0.10 & 2 & 0.20 \\
\hline Bad media exposure on bird flu issues & 0.10 & 3 & 0.30 \\
\hline Total & $\mathbf{1 . 0 0}$ & & $\mathbf{3 . 0 0}$ \\
\hline
\end{tabular}

A combined weighted score of 3.0 shows that thepoultry farm is responding in an exceptionalmanner to prevailing opportunities and threats.This means that the business is capitalizing on its opportunities effectively and minimizing the effects of potential threats efficiently.

\section{External Opportunities}

"Being a basic food item, the chicken egg is a regular component of every family's home. Over the last two decades, the per capita consumption of eggs has risen from 6 to 10 kilograms which only shows that there an increasing demand and consciousness on the need for eggs on every family's table and that only shows that this is great opportunity every egg layer farm business can take advantage so as for the continuous profitability of this business [13]."

According to the Manager of MM Anupol, since the farm is using a self-mixed feeding system, instead of buying commercial feeds, they have a nutritionist who formulates the feeds for the laying chickens. The availability of such inputs in the market is very necessary. "There are many companies available throughout the world, which are producing commercial feed and feed supplements for layer chickens [6]." These can be bought from local market thus the manager need to be sure that the feed and feed supplements they purchased are supplemented with vitalnutrients so as to increase its life span and decrease mortality rate.

The employees mentioned thatthey need to adopt the latest technology in poultry raising. They need to enhance their environmental control, automation in feeding, drinking and other management [14] and since there is an availability of high technology farm facilities in the market, if the business would like to shift from conventional housing to modern one, they could always take advantage of this opportunity to increase and enhance their production.

"The continuing survival and growth of the Philippine poultry industry therefore depends on its ability to compete in the local and global market, which, in turn, depends largely on the efficiency of its production and marketing systems [14]." Creating strong functional relations between the owner and the stakeholders is very necessary for the business owners to create loyalty to all of their stakeholders especially to their employees, distributors, suppliers and consumers.

As of 2018, based on the Business Permit and Licensing Office of the municipality of San Isidro, there are only 2 existing commercial layer poultry farms in the town which means that the MM Anupol Poultry Farm is operating under the duopoly market structure. Due to this 
market control, these firms have the ability to influence the entire market. "Dominating market players are able to create barriers of entry for new entrants, thereby making it difficult for them to get into the business and that mean less competition on the part of this business owners [15]."

\section{External Threats}

The business owner has revealed some of the threats they have been encountering since the company had been established 58 years ago. He stated thatrise and fall of their business depend largely on good management, choice of chicken layer breed, readiness for disease outbreak, quality of egg and feed efficiency."The advances in feeds formulation influence the increase in the efficiency of chicken layers to produce eggs [13]." Since the MM Anupol Poultry Farm is applying the ad libitum in feeding their chickens and is using their own formulation of feeds, the high cost inputs (raw materials and medicines) has become a threat.

According to [16], "the first bird flu outbreak in the country has spread to two towns in Nueva Ecija, which include the municipality of San Isidro, where over 300,000 poultry had been culled." This kind of disease outbreak could immediately ruin the business without any control of the owners. This issue was also worsened by fake news and bad media exposures.

Another threat in a poultry business is temperature or theclimate in a chicken house. It plays a great influence in the health and production level of the chickens especially those young and productive birds. An ambient temperature between 20 and $25^{\circ} \mathrm{C}$ fits the laying hen best. When layers are exposed to much higher temperatures, the birds would be looking for cooler places; there is less activity; the birds start panting and spreading their wings in order to increase their body surface; water consumption increases and feed intake drops; egg production drops; egg weight decreases; shell quality and strength decrease [17] thus, creating a negative impact in the egg production business.

In addition, a flock of pullets or layers can only perform up to its genetic potential when disease influenced is minimized. The diseases of economic importance vary widely between locations, but in every case the challenge is to identify and control those diseases. "Biosecurity is the best method of avoiding diseases. A good biosecurity program identifies and controls the most likely ways a disease could enter the farm [12]."

Lastly, in every business there is always a risk of having new competitors. When fresh competitors move in and offer similar products, their poultry's competitive position will be at risk. Therefore, the threat refers to the ability of the new poultry farmto enter in the industry that can lead toupsurge in the company's market share and lesser profit or worst may lead to losses if they cannot sustain their market.

\section{CONCLUSION}

1. The MM Anupol Poultry Farm is a stable business which already exists for 58 years and under the Closed Corporation form of business.

2. For the Internal Factor Evaluation (IFE) Matrix, the poultryis considered a strong in their industry position which means that its internal position is good.

3. For the External Factor Evaluation (EFE) Matrix, the poultry is responding in an excellent manner to existing opportunities and threats to the industry.

4. The firm's strategies is capitalizing on its opportunities effectively and minimizing the effects of potential threats efficiently.

\section{RECOMMENDATION}

1. The business owners of MM Anupol Poultry Farm should consider improving its biosecurity control in the site to avoid diseases of chickens

2. The business owners must consider transforming their housing from conventional type into a modern based one.

3. Improvement may be made by the owners of the MM Anupol Poultry Farm regarding investments in breeding and genetic improvements to produce its own breeder stock and integrating forward into further processing and distribution of eggs.

4. Other studies on evaluating businesses like egg layer poultry farm should be done by future researchers through the application of other analysis tools like PEST Analysis, TOWS Matrix and other strategic management tools.

\section{REFERENCES}

[1] Sami K. Al-Khamaiseh (2014). Analysis of Egg Production System at Al-Karak Governorate in Jordan.file:///C:/Users/mypc/Downloads/A1Khamaiseh4192014ARRB9907 1\% 20(2).pdf

[2] Kokemuller, N.(2018).Purpose of a SWOT Analysis. https://s mallbusines s.chron.com/purpose-swotanalys is $-15364 . \mathrm{html}$

[3] Manuel B. and Medel, P.(1976). A Practical Guide to Methodology of Research and Thesis Writing. Manila: GIC Enterprises and Company, Inc.

[4] Calderon, J.(1993). Methods of Research and Thes is Writing. National Bookstore: 125 Pioneer St., Mandaluyong City, Philippines. 
[5] David, F.R. (2011). Strategic Management: Concepts and Cases. 13th ed. FT Prentice Hall.

[6] GrowelAgrovet Private Limited (2015). Layer Poultry Farming Guide For Beginners.

https://www.growelagrovet.com/layer-poultry-

farming/?fbclid=IwAR0AJB1mtuNPZ5L-

fTfmPxSKQZXVplT --

Sdu6DCJMoutB20w1U1 5QNts

[7] Bos, J.F.F.P., Van De Ven, G.W.J., 1999. Mixing specialized farming systems in Flevoland (The Netherlands): agronomic, environmental and socioeconomic effects. Netherlands Journal of Agricultural Science47, 185-200.

[8] Mollenhorst,H., 2005. How to house a hen.Assessing sustainable development of egg production system.PhD-thesis, Wageningen University, The Netherlands With ref. - With summary in Dutch and Englsih - 136 pp. ISBN 90-8504-253-4.

[9] Bureau of Agriculture and Fisheries Standards (2015).Code of Good Animal Husbandry Practices for Poultry - Broiler and Layers.

[10] Poultry Manual. Poultry Egg Production in the Philippines(n.d.): How to Produce Safe Eggs at Home. https://poultrymanual.com/category/eggs -marketphilippines/?fbclid=IwAR08Yzf6PDn 8a309Rob6Dtq AiJW sbCHxGg-t1eSTuq9tfhgAyN2vBLGwTQ

[11] Butcher, G. D. and Miles, R. D. (2012).Disease Prevention on Commercial Poultry. https://edis.ifas.ufl.edu

[12] Hy-Line Brown (2009).Commercial Management Guide.Intensive or Extensive.

https://www.hyline.com.au

[13] Nagy, Katalin (2012). "Integrated Solutions," International Poultry Production, August 2012.

[14] Chang, H.S. 2005. "Analys is of the Philippine Chicken Industry: Commercial versus Backyard Sectors". Asian Journal of Agriculture and Development, Vol. 3, Nos. 1, University of New England.

[15] Businesszeal (n.d.).The Principal Advantages and Disadvantages of Oligopoly.

https://bus inesszeal.com/advantages -dis advantages-ofoligopoly?fbclid=IwAR2Gxriacu3fPuXPSjmduhYWd QAfPcozzDMa324aw8wRj21QNjdgH7jey9Q

[16] Simeon, Louise Maureen (2017). It's confirmed: Bird flu spreads to Nueva Ecija. https://www.philstar.com/headlines/2017/08/18/17306 38/its-confirmed-bird-flu-s preadsnuevaecija?fbclid=IwAR3h0p9yL5zLWbJIATCcMy2 GmoeDvKUHRnRigQ7qJSnvBX2GkUQJPbXAc\#t 3aCfVTby4J YFFqU.99
[17] Gietema, Bart (2005). The Basics of Chicken Farming (in the tropics). ISBN: 9052850062 NUGI: 835 